\title{
DOS ASPECTOS EN EL CONCEPTO DE BIENESTAR
}

Introducción

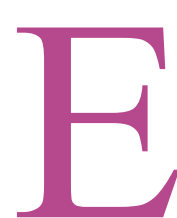

1 concepto de bienestar es, sin lugar a dudas, un concepto evaluativo y gradual. Atribuir más o menos bienestar a un sujeto es darle un valor más o menos positivo a su vida; de manera que la elucidación del concepto de bienestar supone contestar, por lo menos, a dos preguntas: Primeramente ¿en virtud de qué circunstancias, aspectos o características de la vida de una persona hemos de atribuir bienestar a esa persona? y, en segundo lugar, una vez determinados los objetos sobre los cuales haya de hacerse la evaluación, ¿cómo hemos de «medir» el bienestar de las personas de manera a hacer posibles las comparaciones interpersonales de bienestar? Esta segunda pregunta es de interés primordial para aquellos economistas y políticos cuya función social es la de proponer estrategias que favorezcan una distribución equitativa de todos aquellos bienes que de una $\mathrm{u}$ otra manera inciden en el bienestar de los ciudadanos. En este trabajo intentaré presentar algunas dificultades que supone contestar adecuadamente a la primera pregunta, presentando para ello cuatro concepciones diferentes del bienestar, y sólo en la parte final me referiré a algunos problemas que plantea la segunda pregunta al examinar la versión del bienestar que nos propone Amartya Sen ${ }^{1}$.

El concepto de bienestar parece ser un concepto mixto en el que se combinan características de dos tipos diferentes: por un lado, características que aluden a circunstancias exteriores de la

${ }^{1}$ Véase especialmente A. Sen. On ethics and $(E \& E)$. Brasil Blackwell, Oxford, 1987, y sus artículos «Rights and Capabilities» («R\&C»), en Ted Honderich(ed.), Moral Objectivity, Blackwell, Oxford. 1986, y, «Capabilities and Well-Being» (C \& WB». que aparecerá en M. Nussbaum y A. Sen (eds.), Quality of life. Clarendon Press, Oxford. 
persona, tales como su posesión o acceso a ciertos bienes materiales o externos, por ejemplo, su riqueza, su poder, las comodidades con las que cuenta, el tiempo libre del que dispone, su acceso a servicios de salud y de educación y por otro lado, características que aluden a la posesión de ciertos estados internos de la persona o estados de ánimo considerados como valiosos, como por ejemplo, el placer, la felicidad, el contento, el sentimiento de dignidad, la esperanza y, en general, todo aquello que resulta de la realización de deseos, anhelos y planes de vida personales. Como diría Aristóteles, nadie llamaría dichoso a quien teniendo riquezas y salud se la pasara durmiendo o tuviera un ánimo contristado y, deprimido, como tampoco llamaríamos dichoso a quien careciera de ciertos bienes externos indispensables para el desarrollo adecuado, una casa digna, la oportunidad de educarse, el acceso a cuidados sanitarios; esto es, todo aquello que brinda oportunidad a la persona para participar en aquellas «acciones que la virtud exige»(Politica 1323 b, 42 43). Tal parece, en efecto, que al atribuir bienestar a una persona nos fijamos tanto en qué tan bien está desde el punto de vista exterior o material como en qué tan bien se encuentra anímica o interiormente. Dependiendo de la manera como se combinen estos dos factores en una explicación del bienestar, tendremos concepciones diferentes del bienestar humano, y en la medida en que alguno de sus dos aspectos se encuentren ausentes, tendremos concepciones, en mi opinión, incompletas o inadecuadas.

En las distintas secciones de este trabajo exploraré diversas concepciones del bienestar que, como dije, combinan de diferentes maneras los aspectos señalados, e intentan apuntar a algunos problemas que suscitan.

\section{La concepción aristotélica del bienestar}

Aristóteles en su Ética Nicomaquea (1098 b, 13-18) recoge

una doctrina antigua y aceptada por los filósofos, «según la cual los bienes se clasifican en tres tipos: los bienes externos, los bienes del cuerpo y los bienes del alma o psíquicos»». Estos tres tipos de bienes parecen contribuir de diferentes maneras al bienestar total de una persona. En la Política (1323 a 24) sostiene explícitamente

${ }^{2}$ La traducción de la $E N$ que utilizo es la de Antonio Gómez Robledo, publicada en la colección Bibliotheca Scriptorum Graecorum et Romarorum Mexicana, UNAM. México, segunda edición 1983. La idea expresada en la cita a continuación se halla reiterada en la Política, libro VII, cap. 1. (132a. 23). 
que «estos tres ingredientes tienen que hallarse presentes para hacernos dichosos». La posesión de cada uno de estos tipos de bienes daría lugar, por así decirlo, a diferentes tipos de bienestar: el bienestar exterior o material, el bienestar corporal (salud y belleza física) y el bienestar interior o anímico. Estos son enteramente diferentes entre sí, pues la suma de cualesquiera de dos de ellos no daría lugar al tercer tipo de bienestar. Concretamente. el bienestar anímico, el único deseable por sí mismo, no es la suma resultante de la posesión de bienes externos y del bienestar corporal, pues como bien señala Aristóteles es posible tener riqueza, poder y salud y no tener el bienestar más valioso que sería el propio del alma humana: la eudemonia o auténtico bienestar que es peculiar a los humanos.

La relación entre esos tipos de bienes que podemos distinguir no es cosa fácil de establecer (cfr. Política 1323 a. 32-33). Aristóteles como es bien sabido. jerarquiza los bienes antes mencionados y considera en un nivel inferior a los bienes externos y corporales y en un nivel superior a los bienes anímicos. Los primeros, nos dice, no son más que bienes instrumentales, es decir, son medios para la obtención de otros fines; no los deseamos por sí mismos, sino por el bienestar interior que pueden procurarnos. Por otra parte, de entre los bienes anímicos el placer no es el más alto de todos; hay también una jerarquización de bienes anímicos según que correspondan a las diferentes partes del alma. El placer es el resultado de la satisfacción de nuestros deseos o apetitos no necesariamente informados por la razón práctica o guiados por la prudencia. Sólo la actividad conforme a la razón, esto es, la actividad peculiar del hombre, puede conducir al verdadero bienestar humano, a la eudemonia; sólo ésta es autosuficiente o valiosa en sí misma, pues es, según dice Aristóteles. «el único bien que torna la vida amable y ya de nada menesterosa» (EN. 1097 b. 15). Ahora bien, la única manera como podemos alcanzar este supremo bien es mediante la práctica virtuosa, es decir, mediante el hábito de actuar racionalmente en las distintas esferas de la vida. Sólo esta manera de actuar nos llevará a elegir lo que realmente vale la pena elegir y a desear lo verdaderamente deseable, es decir, lo que nuestra razón, no nuestro apetito, nos presenta como deseable.

Hay que advertir que tanto la actividad motivada por deseos apetitivos no racionales, como la actividad virtuosa conforme con los deseos racionales traen como consecuencia el placer, pues ambos tipos de actividad suponen la realización de deseos, lo cual, en la concepción aristotélica, es en sí mismo placentero. Sin embargo, Aristóteles enfatiza una y otra vez que lo verdaderamente 
deseable no lo hacemos por el placer que conlleva su realización, sitio que lo deseamos por sí mismo, porque nuestra razón nos lo presenta como algo en sí mismo deseable o valioso: sólo cuando nuestra actividad es motivada por deseos de éste último tipo, produce en el agente el auténtico bienestar, la eudemonia. la cual, a diferencia del placer que es efímero o pasajero, es una cualidad anímica estable, duradera.

Cabe notar que aún cuando Aristóteles sitúa el único bienestar genuino, la eudemonia, en la actividad que resulta de la operación de una facultad anímica, no deja de considerar como una condición necesaria para la realización de acciones virtuosas el tener una buena proporción de los otros dos tipos de bienes: los externos y los corporales. Así en EN 1099 a, 30-1099 b, 10 (Véase también Política, libro VII, Cap. 1) afirma: «manifiesto que la felicidad reclama bienes exteriores... Es imposible, o por lo menos muy difícil, que el que está desprovisto de recursos haga nobles acciones... No sería precisamente feliz quien tuviera un aspecto repugnante, o fuese de linaje vil, o solitario y sin hijos, y menos aún aquél cuyos hijos o amigos fuesen del todo perversos, o que siendo buenos viniesen a fallecer... la felicidad parece exigir un suplemento de prosperidad... y de ahí que algunos identifiquen la felicidad con la fortuna». La felicidad, entonces, aunque declarada por Aristóteles en otros pasajes autosuficiente, no parece serlo tanto, pues parece depender en buena medida de la suerte, es decir, de en dónde le toque a uno nacer y vivir, de cuáles sean las circunstancias externas que rodean la vida de una persona. Lo cierto es que en la concepción aristotélica del bienestar, el destino o la suerte juega un papel importantísimo; prueba de ello, por ejemplo, es que en la enumeración anterior de las cosas que obstaculizan la felicidad, alude a características personales (como el aspecto repugnante) que no estarían en nuestras manos corregir, y a eventualidades (como la muerte de los hijos o amigos,) que caen totalmente fuera de nuestro control.

Hay varios rasgos interesantes de destacar en la versión aristotélica del bienestar:

1. En primer lugar, para atribuir bienestar a una persona hemos de tener en cuenta antes que nada qué hace y cómo lo hace, esto es, hay que fijarse en cómo actúa o cómo funciona. La felicidad consiste en un modo de actividad: la actividad racionalmente dirigida. «La felicidad -afirma Aristóteles- es una actividad del alma conforme a la virtud». (EN, 1102 a, 5-6). Nótese que las virtudes para Aristóteles no son meras disposiciones que pudieran nunca manifestarse, son hábitos de operación, son formas efectivas de comportamiento, son maneras de funcionar 
en las distintas esferas de la experiencia humana ${ }^{3}$. La vida feliz es, pues, la vida activa, el ocioso o el que duerme no puede ser propiamente feliz. (EN, 1099 a, 1-2.)

2. La felicidad no es un bien entre otros bienes. Es cualitativamente otra cosa: «Ella es aún más deseable que todos los bienes y no está incluida en la enumeración de éstos.» (EN, 1097 b, 17-18). Esto es, la felicidad no consiste en la obtención de placeres ni en la posesión de ningún conjunto de bienes externos o corporales. Estos «son por naturaleza auxiliares y útiles por modo instrumental» $(E N, 1099 \mathrm{~b}, 28)$, pero tenerlos no constituye la felicidad. La felicidad, pudiéramos decir, es una propiedad que sobreviene naturalmente en la persona cuando ésta adquiere el hábito de actuar racionalmente, es decir, cuando la persona se hace un carácter que la lleva a realizar acciones virtuosas. Es, además, un bien interno a dicha moralidad de nuestra actividad en el sentido de que no podemos identificarla independientemente de ella; es decir, no es nada externo a la actividad misma.

3. Dado que la acción supone necesariamente la realización de deseos por parte del agente (racionalmente dirigidos en el caso de la acción virtuosa), la virtud, lejos de producir sufrimiento o frustración en el agente es placentera y deleitosa. «Las acciones conforme a la virtud serán en sí mismas deleitosas... la felicidad... es lo mejor, lo más bello y lo más deleitoso» $(E N$,

1099 a, 20-25.) Esto es, el hombre virtuoso es aquel que tiene deseos de realizar nobles acciones $\mathrm{y}$, dado que las virtudes son hábitos, aquel que tiene permanentemente deseos de realizar dichas acciones de tal manera que siempre se deleita en ellas, pues «para cada cual es placentero aquello a lo que se dice ser aficionado» (ibid). Más aún, el placer es uno de esos bienes necesariamente comprendido en la felicidad ( $E N, 1099$ b, 26); no llamaríamos feliz a quien no obtuviera placer en la realización de sus acciones, «las acciones ajustadas a la virtud... son deleitosas para los virtuosos y deleitosos en sí mismas. La vida de estos hombres para nada demanda por añadidura el placer... sino que tiene en sí misma su contento» $(E N, 1099$ a, 13-16).

4. La felicidad es estable, no es algo como la suerte que va y viene, ni como el placer que es efímero. «Si seguimos el curso de la suerte -dice Aristóteles- diremos del mismo hombre que algunas veces es feliz y otras desdichado, haciendo así del hombre feliz una especie de camaleón o de edificio miserable fundado»»

${ }^{3} \mathrm{Cfr}$. EN, Libro II, cap. 8. en donde Aristóteles introduce las distintas virtudes por referencia a los diferentes ámbitos de nuestra experiencia. 
(EN, 1100 b , 5-8) o, en otro contexto, «ni un día ni un corto tiempo hacen a nadie bienaventurado o feliz» (EN, 1098 a, 1820). La felicidad, no es pues la buena fortuna, ni un estado de ánimo pasajero como puede serlo el placer, es una manera de ser de la persona, es el tener un conjunto de virtudes, un carácter, que acompaña al hombre toda la vida: «La estabilidad, de cierto, se encontrará en el hombre feliz, que será tal por toda su vida.» (EN, 1100, 19-20.)

Veamos brevemente cómo se relacionan en Aristóteles los distintos tipos de bienes que de alguna manera inciden en el bienestar de una persona. Los bienes externos y corporales son tales sólo por la función instrumental que cumplen. Su posesión puede brindarnos placeres, los cuales, como dijimos, son bienes anímicos pasajeros y de segunda categoría, pues ningún acopio de estos placeres constituye el auténtico bienestar. Por encima del placer que podemos experimentar en la realización de acciones motivadas por deseos meramente apetitivos, está el bienestar resultante de la realización de acciones que satisfacen nuestros deseos informados por la razón, esto es, la felicidad que engendra la actuación virtuosa. Ésta es el más alto bien porque supone la operación de la razón, de la facultad distintiva del hombre, la cual guía la actuación del hombre virtuoso en todos los ámbitos de su vida, favoreciendo, así, la realización plena o el florecimiento de su persona. Ésta es el genuino bienestar, el cual, como señalábamos antes, no excluye el placer ni la posesión de bienes externos, sino que, por el contrario, los supone, pero no se identifica con ellos.

Podemos observar una cierta tensión en la concepción aristotélica de la felicidad. Por un lado, Aristóteles insiste en la capacidad del hombre para lograrla por sí mismo y sostiene que «puede adquirirse por la virtud o por cierto estudio o ejercicio» $(E N, 1099$ b, 15-16), que «es asequible mediante cierto estudio y diligencia a todos aquellos que no estén lisiados para la virtud» $(E N, 1099 \mathrm{~b}, 18-20)$ y que constituiría «un grave yerro encomendar al azar lo más grande y lo más bello» (EN, 1099 b, 23-24). Sin embargo, por otro lado, Aristóteles no deja de contemplar el destino o la suerte como un factor esencial en nuestras vidas que puede facilitar o entorpecer la realización del bienestar. Así, por ejemplo, en esta vena afirma: «Si los sucesos de la fortuna son grandes y frecuentes y resultan mal, oprimen y estragan la felicidad, porque acarrean tristezas y entorpecen muchas actividades» (EN, 1100 b, 28-30). Hemos observado también que el ejercicio de la virtud requiere de bienes externos y corporales «cuya adquisición... se debe o bien a una mera coincidencia o a la fortuna» 
(Política, 1323 b, 28), es decir, que pueden no estar de ninguna manera a nuestro alcance. Aristóteles parece, pues, titubear entre considerar que podemos bastarnos a nosotros mismos para alcanzar la felicidad, la cual sólo dependería del carácter que con nuestro esfuerzo nos forjemos, y considerar que somos enormemente frágiles ante las eventualidades de la fortuna ${ }^{4}$. (Tal vez esta última sea una intuición que muchos compartimos). En la Política (1331 b, 39-41) sostiene directamente que no todos los hombres tienen oportunidad de vivir bien y que esto puede deberse o bien a su naturaleza, o bien a golpes de la fortuna o a la carencia de recursos materiales.

Podemos preguntarnos ahora qué obligaciones para el Estado engendra esta concepción aristotélica del bienestar. Dado que para Aristóteles el mejor Estado (politeia) es aquel en el que se maximizan las posibilidades de bienestar, esto es, las posibilidades de actuar virtuosamente de los ciudadanos (cfr. Política, libro VIII, cap. 13), parecería que su primera tarea debería ser la de disminuir al mínimo el elemento de azar que, según él mismo reconoce, puede hacer imposible la felicidad para algunos. Esto es, el Estado debería asegurar, por ejemplo, una distribución adecuada de aquellos bienes materiales necesarios para el ejercicio de las virtudes. Sin embargo, en este respecto, Aristóteles como buen hombre de su tiempo, considera el destino como inevitable, como parte de lo que conforma una vida propiamente humana. De tal manera que habría ciertos límites infranqueables para la acción del Estado, ya que éste no podría cambiar lo que depende de la fortuna. Así, afirma en la Política, «[doy] por supuesto que la Fortuna es soberana» (1332a, 31-32). Lo ártico que sí está en manos del Estado, según Aristóteles, es educar a los ciudadanos en la virtud inculcando en ellos el hábito de la actuación racional en las distintas esferas de la vida. En la Política, Aristóteles dedica largos capítulos a lo que debe ser la educación ideal, esto es, una educación que tenga por fin la formación de un carácter virtuoso, que haga que el joven desea lo verdaderamente deseable y se deleite en el ejercicio de las virtudes ${ }^{5}$. Pues quien llegue a actuar virtuosamente tendrá casi asegurada la felicidad y, si le sobreviven en grandes desgracias. «llevará los cambios de la fortuna con sumo decoro y guardará en todo una perfecta armonía, como varón verdaderamente esforzado» $(E N, 1100 b, 20-21)$; aún en esas circunstancias, asegura Aristóteles.

${ }^{4}$ Para un estupendo estudio de este problema. Véase M. Nussbaum, The fragility of goodness, Cambridge Universasity, Press, Cambridge, 1986.

${ }^{5}$ Cfr. Aristóteles, Política, Libro VII, caps. 13-17 y Libro VIII. 
«se difunde el resplandor de la hermosura moral cuando un hombre lleva con serenidad muchos y grandes infortunios, no por insensibilidad al dolor, sino porque es bien nacido y

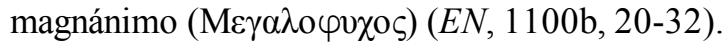

La propuesta aristotélica tiene la virtud de apreciar la complejidad inherente a la noción de bienestar. Esto es, considera que en el genuino bienestar de una persona es una combinación de factores externos e internos y atinadamente escoge a los actos humanos como los objetos en los que hay que fijarse si queremos evaluar el bienestar de una persona. Sin embargo, el peso que concede al destino es demasiado grande y, por lo mismo, las posibilidades que atribuye al Estado de promover el bienestar humano parecen limitadas.

Hay, por lo menos, dos maneras de superar la dificultad que supone la idea aristotélica de «destino»: por una parte. es evidente que podemos «adelgazarla» o eliminarla parcialmente en una explicación del bienestar humano si consideramos que no necesariamente abarca todo lo que Aristóteles pensó que abarcaba, concretamente, que no es debido a un destino inevitable que una persona es pobre o desnutrida o incapaz de disfrutar de ciertos bienes culturales. Por otra parte, se puede argumentar en contra de la fragilidad que Aristóteles atribuya a los humanos frente a los embates de la fortuna; es decir, se puede argumentar que estamos hechos de tal manera que somos capaces de no ser afectados interiormente por las circunstancias exteriores de la manera como Aristóteles lo supuso. Esta última es la estrategia seguida por los estoicos.

Pasemos, pues, a examinar esa otra propuesta de explicación del bienestar que intenta eliminar la influencia del azar sobre la felicidad, y que hace esto ordenando de una manera enteramente diferente a la aristotélica los dos ingredientes en el concepto de bienestar que distinguimos, al principio de este trabajo. Veamos. pues, el ideal estoico del bienestar.

\section{El bienestar estoico}

Para los estoicos no hay más bienestar que el interno. Al igual que Aristóteles, los estoicos sostienen que alcanzamos el bienestar, la felicidad, a través de una vida virtuosa. Sólo que, a diferencia de Aristóteles, la virtud para ellos no es más que una sola y consiste en conocer y aceptar el logos natural. Ser feliz, según el viejo Zenón, es, «vivir en armonía con la ley de la naturaleza». El hombre sabio es el que mediante su razón conoce la 
ley que rige la naturaleza y comprende que todo lo que acontece sucede conforme a un plan supremo al que se somete de buen grado. Ninguna de las cosas externas que espontáneamente consideramos cono buenas o malas son realmente tales. todo es en sí mismo indiferente ${ }^{6}$. Nada de lo que acontece y está fuera de nuestro control tiene un valor en sí mismo; lo único intrínsecamente bueno o malo es el estado de ánimo con el que recibimos los acontecimientos, «Es bienaventurado -dice Séneca- el hombre para el que no hay nada bueno ni malo, sino el mal ánimo... a quien ni entusiasman ni quebrantan las vicisitudes de la fortuna, que está convencido que no hay mayor bien del que puede darse a sí mismo»? ${ }^{7}$.

Llevar una vida virtuosa, es, pues, mantenerse siempre ecuánime, aceptar sin que nos perturbe cualquier cosa que suceda. Lograr la felicidad, no supone, como lo suponía para Aristóteles actuar dirigido por nuestra propia razón, sino conocer la razón universal y vivir de acuerdo con ella. «¿Cuál es mi propósito? -pregunta Epicteto- entender la naturaleza y seguirla» ${ }^{8}$. Sólo esto nos hará ver la fatuidad de nuestros deseos y nuestros temores, nos permitirá deshacernos de ellos y así, a alcanzar la imperturbabilidad. «Puede llamarse feliz -dice Séneca- el que ni desea ni teme nada gracias a la razón»?.

Los estoicos, al igual que Aristóteles. colocan a la virtud y a la razón en el centro de la discusión sobre el bienestar. Sólo que en los escritos estoicos estas palabras vienen a cobrar un significado enteramente diferente. No hay más razón que la que gobierna el universo, ni más virtud que la vida en armonía con la naturaleza. La felicidad que Aristóteles concebía como una actividad por excelencia, en la filosofía estoica se transforma en pasividad, esto es, vivir sin deseos ni temores y mantener un estado de ánimo imperturbable ${ }^{10}$. Aristóteles apunta a lo contraintuitivo que resulta la caracterización estoica de la virtud y el bienestar en un agudo pasaje de su Ética Nicomaquea en el que dice: «Paréceme con todo que se trata de un bien aún deficiente, pues cabe la posibilidad de que el hombre virtuoso pase la vida durmiendo u holgando y además de esto, que padezca los mayores

${ }^{6}$ Cfr, G. Kidd. «Stoic Intermediates and the End of Man», en (Classical Quarterly, N. S. V. (1955), págs. 181-194.

${ }^{7}$ Séneca, «De la vida bienaventurada), en Tratados Morales, Tomo I. trad. J. M. Gallegos Rocafull. UNAM. 1944, pág. 9.

${ }^{8}$ Epicteto, Manual, párraf. 49.

${ }^{9}$ Séneca, op. cit., pág. 9.

${ }^{10}$ Véase Séneca, op. cit. págs. 19-20. 
males y desventuras. Nadie diría, a no ser por defender a todo trance una paradoja, que quien vive de esta suerte es feliz.» (1095b, 33-35, 1096a, 1-3).

A pesar de lo extravagante que pudiera parecernos la ética estoica, es, sin embargo, sensible a varios problemas implicados en la caracterización del bienestar. El primero de ellos es tal vez el del relativismo. En efecto, si el bienestar es concebido como un estado interno que requiere para su realización de ciertas circunstancias exteriores a la persona, sería posible que dichas circunstancias pudieran variar de un sujeto a otro y que, por tanto, aquellas que dieran el bienestar a uno no se lo dieran a otro. Al identificar el bienestar con un estado interior que no depende en ninguna medida de la posesión o el disfrute de bienes materiales, ni del hecho de ocupar un determinado lugar en la sociedad, ni de la historia o la fortuna personal, ni de lo que acontezca exteriormente, el bienestar se convierte en algo absoluto. Cuando el estoico atribuye el bienestar o la felicidad a cualquier persona, sabe que le atribuye exactamente una misma cosa: un cierto estado anímico que puede lograr mediante la disciplina personal y que no es de ninguna manera relativo a la historia individual o al contexto sociocultural en el que se despliega la vida de la persona.

Un segundo problema al que es sensible el estoicismo es que si el bienestar o la felicidad, que es aquello a lo que todos naturalmente aspiramos, se identifican con la posesión o el disfrute de bienes exteriores, o si aceptamos que puede verse afectado por cosas o situaciones que caen fuera de nuestro control, entonces podría ser el caso que aún el hombre más esforzado fuera incapaz de lograr el bienestar. Esto sugiere una especie de irracionalidad o de injusticia natural que para los estoicos es simplemente inadmisible. La aparente irracionalidad se elimina al identificar la felicidad con un estado interno de impertubabilidad al que, después de todo, cualquier sujeto puede acceder mediante una cierta disciplina interior ${ }^{11}$.

Conectado con lo anterior, me parece ver más que un problema una tentación a la que cede el estoicismo: la de pensar que el propio bienestar no depende a fin de cuentas más que de uno mismo; esto es, la tentación de la autosuficiencia. Ante la infelicidad, la frustración, la carencia de bienestar exterior, una permanente tentación a lo largo de la historia ha sido la de considerar que el auténtico bienestar depende de un estado interno y

${ }^{11}$ Véase Séneca, La tranquilidad del ánimo, en op. cit., págs. 93-149. 
que es independiente de lo que nos acontezca, de lo que podamos efectivamente hacer, de los bienes externos que tengamos o dejemos de tener. El bienestar depende únicamente de lo que es obra del hombre, de la operación de su mente ${ }^{12}$. El estoico está convencido de la viabilidad de esta propuesta que pudiera parecernos nada más que un signo de soberbia, o un wishful thinking. De esta manera, Séneca nos aconseja «no consideres como bueno o malo nada de lo que sucede... sé inmutable tanto al bien como al mal y, en cuanto sea posible, hazte como la imagen de un dios... nada necesitará, serás libre... nada se te podrá impedir» ${ }^{13}$. De la misma manera en las Mediaciones de Marco Aurelio encontramos reiteradamente la expresión de la convicción estoica referente a la autosuficiencia del hombre para darse a sí mismo el bienestar o la felicidad. En el libro III, por ejemplo, leemos, «si trabajas diligentemente siguiendo la recia razón... sin esperar ni tener nada, sino satisfecho con la actividad... de acuerdo a la naturaleza... vivirás feliz. Nadie podrá impedirte esto...» (párrafo 12).

La concepción estoica del bienestar, tiene el acierto de enfatizar su aspecto interior, esto es. el hecho de que el bienestar tiene que ver esencialmente con la manera como la persona se encuentra interiormente, y hacer esto sin caer en el relativismo. Sin embargo, no son pocos los problemas que presenta el modelo estoico. Mencionaré algunos.

En primer lugar, la teoría estoica de la acción parece contener una cierta inconsistencia al sostener simultáneamente que son permisibles en la vida del hombre feliz las acciones suaves, pausadas, tranquilas ${ }^{14}, \mathrm{y}$, a la vez, que quien alcanzara esto último, perdería una parte indispensable de lo que constituye su razón para actuar. Por esta razón muchos criticarán más tarde a los estoicos por predicar la pasividad y proponer una concepción pasiva de la libertad.

Por otro lado, y conectado con lo anterior, el estoico propone un modelo de bienestar para el hombre que parece suponer precisamente su deshumanización. La vida humana desprovista de su aspecto afectivo y desiderativo se convierte en otra cosa. Si nuestra pregunta es acerca del bienestar humano, resulta inadecuada la respuesta de los estoicos que pretende identificarlos con

${ }^{12}$ Véase F. H. Sandhach, The Stoics, Chatto and Windus. Londres, 1975. págs. 67-69.

${ }^{13}$ Séneca, De la vida bienaventurada, en op. cit., pág. 19.

${ }^{14}$ Cfr. A. A. Long, «Freedom and Determinism in the stoic Theory of Action», en A. A, Long (ed.) Problems of Stoicism, University of London, 1971. 
un estado interno cuya realización supone precisamente la mutilación de una parte de la naturaleza humana.

Otra dificultad no sólo para el estoicismo. sino para cualquier otra teoría que haga depender el bienestar de una persona del hecho de alcanzar algún estado subjetivo, es que puede ser usada ideológicamente para justificar y mantener un estado de injusticia y desigualdad. Esto es, si el bienestar se concibe como un determinado estado subjetivo al que el individuo puede acceder por una disciplina interior, la única obligación pública que engendraría semejante teoría en una sociedad en la que existieran carencias e injusticias (asumiendo desde luego, muy aristotélicamente, que es función del Estado promover el bienestar de los ciudadanos), sería, tal vez, la de educar a los ciudadanos para sobrellevar con entereza sus carencias y tolerar la desigualdad. La educación sería en ese caso un auténtico «opio del pueblo». Aquí apuntamos a una consecuencia política indeseable que parece seguirse de la concepción estoica del bienestar a pesar de no contener ésta, como señalamos antes, ningún ingrediente relativista.

\section{Utilitarismo y relativismo}

Otro es el problema que surge cuando se utilizan criterios subjetivos o psicológicos para caracterizar y medir el bienestar de una persona, pero en donde, a diferencia de la virtud estoica, dichos estados psicológicos dependen causalmente de la obtención de bienes externos o de que se den ciertos estados de cosas que satisfacen los deseos o las aspiraciones individuales del sujeto. Éste es el caso del utilitarismo que, como sabemos, suele ser un supuesto asumido implícita o explícitamente por distintas versiones de la llamada «economía del bienestar» (Welfare Economics) ${ }^{15}$.

El utilitarismo, o, más exactamente, la economía del bienestar que asume la concepción utilitarista del valor, toma como único parámetro para medir el bienestar de una persona su «utilidad individual», la cual suele entenderse en términos del placer o la satisfacción producida por la realización de los deseos o aspiraciones personales. Según esta concepción, la situación de una persona será tanto mejor cuanto menor sea el número de deseos insatisfechos; esto es, a menor frustración corresponderá

${ }^{15}$ Véase las obras de Amartya Sen mencionadas en la n. 1. 
un mayor bienestar. El bienestar de una sociedad, por otra parte es concebida como una función de las utilidades individuales de las personas que la conforman.

La noción utilitarista de valor, se inspira de alguna manera en aquella intuición expresada por Aristóteles en la $E N$, según la cual «toda elección apunta a algún bien») (1095a, 14-15) y «el objetivo de la voluntad es el bien» (1113a, 23-24), pues, en efecto, desear algo consiste precisamente en concebirlo como algún tipo de bien, de manera que consideramos la satisfacción de un deseo como la obtención de un bien ${ }^{16}$. Siguiendo esta intuición, como hemos señalado, las únicas cosas a las que el utilitarista les da un valor intrínseco positivo al calcular el nivel de bienestar de un individuo, son sus deseos satisfechos o el placer que haya resultado de ello. No tocaremos aquí el problema que le plantea al utilitarista el carácter heterogéneo de las «utilidades» que tienen que adicionar para calcular el bienestar de un persona o, peor aún, de una sociedad ${ }^{17}$. Tampoco entraremos en la discusión concerniente a cuál es el conjunto de deseos pertinentes para medir el bienestar, pues se haya eliminado el problema de la contaminación ambiental ${ }^{18}$.

La cuestión que me interesa examinar aquí, es, en primer lugar, la relativización del bienestar que resulta del planteamiento utilitarista y, secundariamente, ver de qué manera un concepto relativizado de bienestar puede ser usado para justificar, o al menos para aceptar con buena conciencia, la injusticia y la desigualdad.

La relativización del bienestar que se desprende de la tesis utilitarista es bastante clara. Para una persona a que tiene un conjunto $X$ de deseos personales, el bienestar consistirá en la realización de la situación en la que se satisfacen precisamente los deseos dentro de $X$; en tanto que para una persona $b$ que tiene un conjunto $Y$, diferente de $X$, de deseos personales, su bienestar consistirá en la realización de esa otra situación. Los conjuntos $X$ e $Y$ pueden diferir tanto como se quiera y correspondientemente

\footnotetext{
${ }^{16}$ Los utilitaristas, desde luego, pasan por alto la distinción aristotélica entre bienes aparentes y bienes genuinos.

${ }^{17}$ Tocaré un problema semejante en la sección IV cuando plantee algunas dificultades para la teoría de Amartya Sen.

${ }^{18}$ Para una buena discusión acerca de la manera como tiene que restringirse el conjunto de deseos de una persona a fin de que pueda funcionar para una evaluación de su bienestar, véase $\mathrm{T}$. M, Scanlon, «Values. Desires and Quality of Life» que aparecerá en M. Nussbaumy A. Sen (eds.) op. cit.
} 
diferirá aquello en lo que consiste el bienestar para $a$ de aquello en lo que consiste el bienestar para $b$.

Veamos mediante un ejemplo simplificado algunas consecuencias que se siguen de la relativización del bienestar. Adoptando el criterio utilitarista, supongamos que realizamos una encuesta a fin de comparar el bienestar de dos grupos de mujeres que viven en contextos socioeconómicos y culturales diferentes, digamos, un grupo de campesinas mexicanas y otro de mujeres que habitan un barrio elegante de la Ciudad de México, Polanco. Suponemos, cosa que no sería de extrañar, que encontramos que las mujeres campesinas declaran tener muy pocos deseos insatisfechos, en tanto que las mujeres de Polanco tienen muchos deseos insatisfechos. Esto, según los utilitaristas, debería bastarnos para concluir que el bienestar de las campesinas es mayor que el de las mujeres de Polanco. Extendamos nuestro ejemplo y digamos que las mujeres encuestadas en Polanco habitan casas sólidas y bien equipadas, visten bien, reciben atención médica adecuada, están bien nutridas, disfrutan de buenos medios de locomoción, tienen un ingreso elevado y han tenido buenas oportunidades de educación, en tanto que las campesinas carecen de todos esos bienes y tal vez hasta desconocen su existencia. Nada de esto último constituiría una razón para el utilitarista para cambiar su primera conclusión. A fin de tratar de desvanecer el aire paradójico de ésta, seguramente, argumentará, que el bienestar de uno y otro grupo de mujeres encuestadas es relativo a su cultura, su medio social, su educación, etc. Esto es, que, dentro de su contexto, la campesina que no demanda mayor cosa, está satisfecha y tiene un alto grado de bienestar, en tanto que la mujer de Polanco tiene un nivel muy bajo de bienestar (o tiene menos bienestar que la mujer campesina) debido a la gran cantidad de deseos insatisfechos. Resulta ahora claro cómo esta noción relativizada de bienestar puede fácilmente ser usada para justificar el hecho de que se tomen medidas tendientes a satisfacer las demandas de las mujeres de Polanco y no se tomen medidas que tiendan a disminuir la desigualdad en oportunidades, comodidades y bienes externos en general entre ambos grupos de mujeres. Esto es, el concepto relativizado de bienestar puede ser usado para mantener precisamente la desigualdad y la injusticia. ¿Qué podemos objetar a esta manera relativista de ver las cosas?

En primer lugar, habría que señalar que la métrica de la utilidad, como puede apreciarse en el ejemplo anterior, puede darnos una idea totalmente deformada de las privaciones o carencias reales de una persona o una comunidad. Una persona que 
haya vivido una vida limitada. desempeñando trabajos duros, sin esperanza de cambio, con pocas oportunidades de educación, puede aceptar las privaciones más fácilmente que otra persona más afortunada que haya vivido en medio de comodidades. Como señala A. Sen «E1 desplazado social aprende a llevar su carga tan bien que ni siquiera se percata de ella» ${ }^{19}$. De manera que si basamos nuestro diagnóstico acerca de qué grupo social tiene menos bienestar y más privaciones sólo sobre lo que los propios integrantes de los grupos estudiados informen sobre sus carencias, nuestro diagnóstico corre un alto riesgo de ser falso.

En segundo lugar, y conectado con lo anterior, cabe señalar que los deseos que una persona pueda formarse en un momento dado, dependen en gran medida de su historia anterior y de lo que considera viable para su futuro. Jon Fister ha estudiado este fenómeno, al que llama «formación de preferencias adaptativas» y que consiste precisamente en un proceso de ajuste, de manera no consciente o deliberada, de nuestros deseos a las posibilidades que juzgamos efectivas, y que está motivado por la necesidad de disminuir la tensión que resulta de tener deseos que sabemos que no podemos satisfacer ${ }^{20}$. El estudio de Elster muestra, no que el bienestar sea relativo, sino que algunos deseos que una persona puede formarse, no sólo son relativos a su contexto sociocultural o incluso a su historia personal, sino que están causalmente determinados por ellos. Si esto es así, parece enteramente inadecuado medir el bienestar de una persona por referencia a la satisfacción de los deseos que de hecho tiene, pues la formación de preferencias adaptativas sugiere que mientras más arraigada esté la miseria y la privación en una persona, menos posibilidades tendrá de desear salir de esa situación.

Por último, quien acepte que el bienestar es relativo a los deseos, a las culturas o a las formas de vida heredadas, tendrá que aceptar que la discusión acerca de en qué consiste el bienestar humano es improcedente, o que si se llega a entablar tal discusión entre personas pertenecientes a diferentes tradiciones o culturas, no habrá acuerdo posible. Lo que para una cultura constituya el bienestar, podrá no constituirlo para la otra, y no habrá un concepto general de bienestar que pudiera servir para dirimir las diferencias. Una consecuencia directa de lo anterior sería la imposibilidad de hacer evaluaciones o criticas racionales, desde una cultura, concerniente, por ejemplo, al poco bienestar

${ }^{19}$ A. Sen, «R \& C», pág. 131.

${ }^{20}$ Véase J. Elsier, «Rationality», en su libro Sour Grapes, Cambridge Univ. Press, pág. 25. 
existente en otra cultura alejada. Así, si yo critico la manera como viven los tarahumaras y asigno un valor muy bajo al bienestar existente entre ellos porque juzgo que tienen necesidades no satisfechas, se me podrá contestar que estoy juzgando su bienestar con mis criterios de bienestar y que esto es inadecuado, pues tal vez esa forma de vida que yo critico constituye para ellos su bienestar. Pero, ¿qué puede querer decir esto? Seguramente que sus deseos, así como lo que ellos crean que son sus necesidades, son diferentes de los míos y que su bienestar está en función de la satisfacción de sus deseos y supuestas necesidades y no de los míos $^{21}$.Vemos aquí nuevamente de qué manera el relativismo sienta las bases para justificar acciones sociales que tiendan a mantener la desigualdad y la injusticia.

Lo anterior, además, supone una cuestión sumamente discutible: que no sólo los deseos, sino las necesidades de las personas son relativas a las culturas o tradiciones a las que pertenecen. Esto puede ser tal vez el caso para algunas de las cosas que llamamos «necesidades», por ejemplo, mi necesidad de tener un coche o de leer el Times. Pero ¿son acaso todas las necesidades humanas relativas a las culturas? Algunos filósofos, como es bien sabido, han defendido la existencia de necesidades absolutas ${ }^{22}$, las cuales de ninguna manera se restringirían a las puramente biológicas. Si éstas existen efectivamente, el alegato relativista perderá sustento, pues tendrá que admitir que, al menos, el acceso a algunos bienes materiales, a aquellos necesarios para la satisfacción de necesidades no relativas, forma una parte esencial de lo que es el bienestar.

Sostener que el bienestar tiene un núcleo de factores no subjetivos, no nos obliga a la rigidez ni al autoritarismo. Es posible considerar que el bienestar humano requiere de ciertas condiciones objetivas universales, pero, a la vez, sostener que dichas condiciones pueden realizarse de diferentes maneras en distintos contextos sociales o culturales. Por ejemplo, si consideramos que tener una habitación digna y vestir de manera que la persona no sienta vergüenza son factores que inciden en el bienestar de la persona, es claro que la manera como se satisfagan estas condiciones para el caso de un minero siberiano, será distinta de aquella como se satisfacen para el caso de un aborigen de la selva lacandona. Lo importante es que en ambos casos el cumplimiento de aquellas condiciones objetivas permitan a las personas

${ }^{21}$ Esta manera de argumentar pone de manifiesto la conexión entre el relativismo y la concepción subjetiva utilitarista del bienestar.

${ }^{22}$ Véase David Wiggins, «Clamas of Need», en Ted Honderich (ed.), op. cit. 
la realización adecuada de ciertas funciones. Y con esto llegamos a la parte final de este trabajo.

\section{Funcionamiento y capacidades}

$\mathrm{Si}$ al elucidar el concepto de bienestar se parte de que tiene ingredientes objetivos y subjetivos, pero se pone demasiado énfasis en su aspecto subjetivo o psicológico, hemos visto que se llega irremediablemente a una posición relativista ${ }^{23}$. Es, pues, natural que las diferentes propuestas que intentan rescatar un concepto no relativo de bienestar destaquen muy especialmente el aspecto objetivo al que nos referimos al inicio de este ensayo. El problema que pueden presentar algunas de estas explicaciones del bienestar que lo conceptúan en términos, por ejemplo, de las nociones de «acceso a los bienes sociales primarios», o de «igualdad justa en la distribución de recursos», o de «igualdad de oportunidades para todos», es que, si bien señalan condiciones aparentemente necesarias para el bienestar, tal vez éstas no sean condiciones suficientes para lograrlo. Recordemos las objeciones de Aristóteles que aluden a lo absurdo que parece atribuir bienestar a quienes se la pasan dormidos u holgando.

Hay, sin embargo, una teoría reciente sobre el bienestar que parece escapar a las objeciones aristotélicas y la razón de esto, es que parece tener como uno de sus ancestros a la propia teoría aristotélica del bienestar. Me refiero a la teoría de Amartya $\mathrm{Sen}^{24}$, que explica el bienestar en términos de lo que él llama «funcionamientos» $\mathrm{y}$ «capacidades».

Sen, a la manera de Aristóteles. concibe a la persona humana como esencialmente activa. La vida de una persona, nos dice Sen, es una variedad de seres y haceres cuyos elementos constitutivos son lo que él denomina «funcionamientos». «Un funcionamiento es un logro de una persona: algo que consigue ser o hacer» ${ }^{25}$. La noción más cercana a la de funcionamiento es, tal vez, la de actividad, aunque no son exactamente la misma noción, pues entre las cosas que Sen considera como funcionamiento, están, por ejemplo, el estar bien nutrido, el no sentir vergüenza de aparecer en público, el escapar a la enfermedad y la muerte prematura. Ahora bien, si la vida de una persona es

${ }^{23}$ Excepto para el caso de la concepción estoica que, como vimos, niega que el bienestar incluya algún factor externo.

${ }^{24}$ Véase las obras de A. Sen citadas en la nota 1.

${ }^{25}$ A. Sen. «C \& WB», pág. 5. 
una combinación de funcionamientos, entonces, evaluar el bienestar de una persona, tiene que tomar la modalidad de una ponderación de los elementos que la constituyen, esto es, sus funcionamientos. Sin embargo, Sen considera que evaluar lo que la persona de hecho hace o es, no es suficiente para tener una idea adecuada sobre su bienestar, pues quedaría fuera de consideración un elemento esencial para el bienestar, a saber, la libertad positiva de la persona, es decir, la posibilidad efectiva de que la persona realice distintos tipos de funcionamientos. Con esto introducimos la segunda noción clave de la explicación de Sen, que es la de «capacidad». La capacidad de una persona, nos dice, «refleja las diferentes combinaciones de funcionamientos que puede lograr una persona $\rangle^{26} \mathrm{y}$, en ese sentido, representa también la libertad positiva de una persona para escoger entre diferentes maneras de vivir: «Las capacidades para funcionar reflejan lo que una persona puede hacer» ${ }^{27}$ y no sólo lo que de hecho hace. Ya armado con estas dos nociones Sen tiene localizados los objetos que hayan de constituir el espacio de la evaluación para el bienestar.

Las ventajas que representa conceptuar el bienestar en términos de funcionamientos y capacidades no son pocas: no son propiedades o características puramente subjetivas (como lo eran las «utilidades» de los utilitaristas) y tampoco son una mera colección de bienes sociales primarios o de recursos a los que el sujeto tiene derecho (en virtud de alguna teoría de la justicia) pero que el sujeto pudiera simplemente desconocer o desaprovechar. Los funcionamientos de los que nos habla Sen requieren de una actitud activa por parte de la persona que normalmente aprovechará los bienes y recursos a su alcance para funcionar. Si el bienestar consiste en tener determinados funcionamientos y capacidades para funcionar, entonces, la relación entre el bienestar y el hecho de tener acceso a ciertas comodidades o bienes externos será muy similar a la que veía Aristóteles, esto es, dichos bienes serán instrumentos indispensables para lograr el bienestar. Por otra parte, al no jugar ningún papel en la teoría del bienestar propuesta por Amartya Sen la noción aristotélica de suertes o de destino, el concepto de bienestar propuesto por Sen puede servir para los fines de orientar la acción pública en el sentido de eliminar desigualdades e injusticias al crear ciertas obligaciones concretas al Estado comprometido con promover el

${ }^{26}$ Ibid.

${ }^{27}$ A. Sen, «R \& C)», pág. 139. 
bienestar de sus ciudadanos, a saber, la obligación de incrementar las capacidades de los ciudadanos para funcionar en los distintos ámbitos de la vida y sobre todo la obligación de asegurar que todos tengan efectivamente las capacidades básicas.

La teoría de Sen no es una teoría acabada. He mencionado varios de sus aspectos positivos y sin duda tiene más. Sin embargo, no deja de presentar algunas dificultades que ahora paso a mencionar.

La primera dificultad que enfrenta Sen está conectado con el problema de la medición del bienestar y es el de tener que asignar diferentes valores a los distintos funcionamientos y capacidades, pues es obvio que no todos tienen la misma importancia o el mismo valor. ¿En base a qué vamos a evaluar los funcionamientos? ¿Cómo hemos de proceder para establecer un ordenamiento valorativo de los funcionamientos? La noción de Sen de «funcionamientos básicos» y «capacidades básicas» podrá tal vez servir para seleccionar aquellos funcionamientos y capacidades que sean condición sine qua non para el bienestar; sin embargo, la selección misma de lo que haya de ser tenido como funcionamiento y capacidades básicas representan en sí mismo un problema; por ejemplo, si decimos que es una capacidad básica el acceso a la educación, tendremos que responder a la pregunta de qué tanta educación. Respecto de los funcionamientos y capacidades no básicas, pueden ser estos tan heterogéneos que si tuviéramos que ordenarlos de acuerdo a su valor no sabríamos por dónde comenzar. En suma, en lo que respecta a cuestiones de medición del bienestar indispensable para las comparaciones intersubjetivas, Sen enfrenta problemas similares a los que enfrentaban los militaristas.

Un segundo problema es que para una evaluación adecuada del bienestar parece que tenemos que distinguir entre mejores y peores funcionamientos de un mismo tipo. Esto es, si vamos a evaluar, por ejemplo, el bienestar de las personas que pintan ¿vamos acaso a darle el mismo valor a la actividad de pintar de un pintor mediano que a la de Tapies o a la de Tamayo? El problema que enfrentamos es el de no saber en base a qué hemos de asignar valores diferentes o iguales a esas actividades. Sen no puede admitir que les asignemos más o menos valor por consideraciones subjetivas, tales como la mayor o menor satisfacción que dichas actividades produzcan en los pintores, pues eso sería tanto como concederles el punto a los utilitaristas. Tampoco puede admitir que el valor que les asignemos esté en función directa de algún «bien externo» logrado; por ejemplo, el dinero que ganen con su pintura, pues son los funcionamientos en sí 
mismos los que son objetos valiosos. Tal vez la calidad de la obra producida pudiera orientarnos para asignar valores diferentes a distintos funcionamientos de un mismo tipo: en el caso de la actividad de pintar esto podría tener una cierta lógica ${ }^{28}$. De cualquier modo, resulta extraño sostener que por no producir obras maestras, la actividad de pintar de un pintor mediano no contribuye tanto a su bienestar como la misma actividad de pintar contribuye al bienestar de Tapies o de Tamayo.

Aristóteles puede responder dentro de su teoría a los dos problemas antes señalados. Dado que lo peculiar al hombre es la razón, nos diría, una actividad será valiosa preciosamente en la medida en que se ajuste a la razón no cualquier tipo de funcionamiento incrementa el bienestar de la persona, sólo la actividad virtuosa promueve efectivamente su florecimiento y de esa manera contribuye a su bienestar. En relación al segundo problema, Aristóteles considera que hay una excelencia (virtud) correspondiente a cada práctica o actividad, de manera que las actividades del mismo tipo serán tanto más valiosas cuanto más se aproximen a la excelencia que les es propia. Independientemente de aceptar o no las soluciones aristotélicas, lo que podemos apreciar es que lo que le permite dar una respuesta a Aristóteles es el trecho de contar con una teoría general del hombre y con una teoría muy refinada de la acción humana. Sen parece necesitar de una teoría semejante, más amplia, dentro de la cual pueda acomodar su teoría del bienestar y que le suministre los criterios necesarios para la selección y evaluación de funcionamientos y capacidades.

Por último, si como dice Sen, la vida de una persona no es más que una combinación de funcionamientos, de esto parece seguirse que cualquier combinación de funcionamientos valiosos que constituya la vida de una persona, será suficiente para atribuirle bienestar. El problema que esto plantea es doble. En primer lugar, parece que hay que exigir que dichos funcionamientos sean variados, de tal manera que pongan en práctica el máximo de nuestras capacidades Y, así, puedan dar lugar al florecimiento de la persona completa. En segundo lugar, una persona cuya vida fuera una combinación de funcionamientos valiosos y variados. pero desconectados entre sí, no parecería ser un buen candidato para atribuirle bienestar. Mac Intyre ha enfatizado

${ }^{28}$ Aunque en ese caso el valor del funcionamiento estaría en función del valor estético de la obra producida, lo cual podría conducirnos nuevamente a cuestiones subjetivas o relativistas. 
en su libro After Virtue ${ }^{29}$ la necesidad de que las distintas prácticas de una persona se hallen integradas en una unidad, en una «narrativa», como él dice, para que constituyan propiamente una vida humana. Esto es, cada vida humana, para ser tal, tiene que poder ser vista como una especie de historia con un propósito, en la que las prácticas que la persona realice hayan de ser elegidas en función de la historia que la persona quiera que sea su propia vida. De esta manera, nuestras actividades presentes, o los funcionamientos de los que nos habla Sen, tendrían que realizarse en vistas a un cierto plan de vida y, así, tener ciertas relaciones con nuestras actividades pasadas y con aquellas que consideramos viables en nuestro futuro. Esto es precisamente lo que te da una unidad y un «sentido» a nuestras vidas y esto, indudablemente contribuye a nuestro bienestar.

Para concluir, diré que las cuatro concepciones del bienestar que hemos examinado apuntan cada una de ellas a alguno o algunos de los ingredientes que sin lugar a dudas que forman parte del concepto de bienestar.

La concepción utilitarista y la estoica, como vimos, resultan parciales en tanto que sólo tienen en cuenta lo que llamé al inicio de este trabajo el aspecto subjetivo del bienestar, y por esta misma razón, como trataré de demostrar, tienen consecuencias inaceptables desde el punto de vista de la justicia cuando se la usa para orientar la acción pública.

La concepción aristotélica y la de Sen, en cambio, tienen la virtud de hacer radicar el bienestar en lo que una persona hace y puede hacer. De esta manera, pueden ofrecer una noción de bienestar que reúne los aspectos objetivos y subjetivos, pues para hacer o poder hacer la persona necesita tener acceso a ciertos bienes o recursos exteriores, y al hacer, esto es, al actual, la persona tiene placer, o tiene satisfacciones interiores para la realización de los deseos o las aspiraciones que motivaron su acción.

El problema que queda pendiente para Sen, y no para Aristóteles. como vimos, es el de determinar conforme a alguna teoría, antropológica o ética, tal vez, cuáles son las capacidades y los funcionamientos que efectivamente inciden en el bienestar de las personas. Sólo un concepto de bienestar así enriquecido, creo yo, podrá servir para orientar las acciones públicas tendientes a promover o asegurar el bienestar general.

${ }^{29}$ A. MacIntyre. After Virtue. Segunda Edición, Univ. of Notre Dame Press. Indiana, 1984. Véase especialmente el cap. 14 y el cap. 16. 

$\triangle$

DOXA-9 (1991) 